\title{
Endoplasmic Reticulum Stress and Microvascular Endothelial Dysfunction in Diabetes
}

\author{
Modar Kassan, Maria Galán, Soo-Kyoung Choi and Khalid Matrougui*
}

Department of Physiology, Hypertension and Renal Center of Excellence, Tulane University, 1430 Tulane Ave, New Orleans LA-70112, USA

Diabetes mellitus is a chronic metabolic disease characterized by hyperglycemia, due to deficiency in insulin or insulin resistance, and represents a major cause of morbidity and mortality in contemporary societies $[1,2]$. According to the world health organization (WHO), more than 285 million people worldwide suffered from diabetes of which 4 million died in 2010. The prevalence is expected to enhance to 380 million by 2030. Genetic and environmental factors associated with life style such as unhealthy diet, physical inactivity, harmful use of alcohol and tobacco, and obesity contribute to the increasing incidence of diabetes. The situation becomes extremely critical since type 1 and type 2 diabetes compromise the cardiovascular homeostasis. Based on the report of WHO and clinical studies, the direct cause of death for 80 $\%$ of diabetic patients is cardiovascular diseases.

Studies in human and experimental diabetic animal models have reported vascular dysfunction and structural arterial wall remodeling [3-5]. It is well known that endothelial dysfunction is an important risk factor of cardiovascular diseases [6,7]. Several hypothesis and mechanisms documented the relationship between diabetes and microvascular endothelial dysfunction [8,9], which include reduced endothelium-derived relaxing factor (EDRF) release and bioavailability, and enhanced endothelium-derived constricting factors release associated with augmented oxidative stress levels. Despite treatments have progressed, the development of novel effective treatments for patients with vascular complications in diabetes remains a major research goal.

The presence of insulin receptors on endothelial cells is well documented [10] but the role of insulin resistance at the level of the endothelial cell in vascular physiopathology is unclear. A number of studies in humans and genetically modified mice have demonstrated a close association between insulin resistance and nitric oxide (NO) bioactivity. Thus, Steinberg et al. [11] and Wheatcroft et al. [12] reported a direct link between insulin-induced vasodilatation and nitric oxide synthase (eNOS) activity. Additionally, Kuboki et al. [13] demonstrated that insulin regulates eNOS transcription in endothelial cells. Another study by Dr. Quon et al. [14] elucidated that insulin activates eNOS by insulin receptor tyrosine kinase (IRS-1) and phosphatidylinositol 3-kinase (PI3K)-dependent mechanisms. These studies support the concept that insulin resistance impairs vascular endotheliumdependent relaxation by PI3K-NO defect-dependent mechanisms. Additionally, It has been shown that insulin increases extracellular signal signal-regulated kinases $1 / 2$ (ERK1/2) and endothelin converting enzyme activity leading to endothelin-1 release increase [15]. Insulin resistance and reduced insulin levels decreased PI3K-NO-dependent signaling, which trigger imbalance between NO and endothelin-1 responsible for impaired vascular endothelium-dependent relaxation [15]. Moreover, the mechanism by which insulin signaling becomes impaired in endothelial cells remains unclear. However, emerging evidence indicates that endoplasmic reticulum stress is an important factor in diabetes-induced pathology [16,17]. Therefore, endoplasmic reticulum stress could be a new potential intermediate signaling that explains the link between insulin resistance and vascular endothelial dysfunction. Various cellular stresses (ischemia, hypoxia, gene mutation, oxidative stress, and increased protein synthesis) lead to impairment of endoplasmic reticulum function, and create a state termed as endoplasmic reticulum stress that leads to the activation of a complex signaling network called the unfolded protein response (UPR) [18-21]. The UPR is regulated in the cell by three endoplasmic reticulum membrane-associated proteins that act as sensors of endoplasmic reticulum homeostasis. The three membrane bound proteins are protein kinase-like endoplasmic reticulum eukaryotic initiation factor $2 a$ kinase (PERK), inositol requiring endoplasmic reticulum to nucleus signaling protein-1 $\alpha$ (IRE1 $\alpha$ ) and activating transcription factor-6 (ATF6).

Metabolic and cardiovascular diseases such obesity, stroke, myocardial ischemia and diabetes are associated with endoplasmic reticulum stress [22-24]. Additionally, endoplasmic reticulum stress is considered as a key element in pancreatic beta cell dysfunction and peripheral insulin resistance in diabetes $[25,26]$. This topic is not discussed here, but a number of excellent reviews in this area have been published [27-29]. In this review, we will focus on endoplasmic reticulum stress as a new mechanism that plays an important role in vascular dysfunction in diabetes. Thus, Ozcan et al. [16,22] demonstrated the first link between insulin resistance and reticulum endoplasmic stress suggesting that ER stress disrupts the mechanism of insulin signaling in liver, adipose tissue and pancreas. Moreover, Ozcan's group also showed that endoplasmic reticulum stress increases c-Jun N-terminal kinase (JNK) and catalytic IkappaB kinase subunits activity, and induces inflammation associated with IRS-1 signaling impairment $[16,22]$ suggesting that endoplasmic reticulum stress is an important factor that probably links obesity, insulin resistance and diabetes to vascular endothelial dysfunction. These observations are supported by: 1) our recent publication indicating that treated type 2 diabetic mice with endoplasmic reticulum stress inhibitor reduced body weight and blood glucose and insulin levels [30], and 2) the occurrence of endoplasmic reticulum stress in endothelial cells in metabolic diseases [31-33], emphasizing that endoplasmic reticulum stress is a potential mechanism that contributes to the reduced nitric oxide release and bioavailability, which leads to vascular endothelial dysfunction. Importantly, it is more likely that endoplasmic reticulum stress impairs vascular function by inflammation and oxidative stress-

*Corresponding author: Khalid Matrougui, PhD, Department of Physiology Center of Excellence for Hypertension and Renal, Tulane University, 1430 Tulane Ave, New Orleans LA-70112, USA, Tel: 504-889-2588; E-mail: kmatroug@tulane.edu

Received October 28, 2011; Accepted November 30, 2011; Published December 15,2011

Citation: Kassan M, Galán M, Choi SK, Matrougui K (2011) Endoplasmic Reticulum Stress and Microvascular Endothelial Dysfunction in Diabetes. J Diabetes Metab 2:108e. doi:10.4172/2155-6156.1000108e

Copyright: ( 2011 Kassan M, et al. This is an open-access article distributed unde the terms of the Creative Commons Attribution License, which permits unrestricted use, distribution, and reproduction in any medium, provided the original author and source are credited. 
dependent mechanisms. Thus, it has been shown that endoplasmic reticulum stress could facilitate eNOS uncoupling, which leads to increase in oxidative stress $[34,35]$ and tumor necrosis factor- $\alpha$ (TNF- $\alpha$ ) production. Furthermore, enhanced TNF- $\alpha$ level in endothelial cells [36] has also been reported to induce endoplasmic reticulum stress that inhibits IRS-1 signaling by JNK and nuclear factor kappa B-dependent mechanisms [37-39]. It is also important to mention that eNOS uncoupling, which leads to oxidative stress generation can also induce endoplasmic reticulum stress in endothelial cells [40]. Together, these studies suggest the existence of potential circle between eNOS uncoupling, oxidative stress, endoplasmic reticulum stress and inflammation responsible for vascular endothelial dysfunction. It is important for future studies to determine the intermediate signaling linking endoplasmic reticulum stress to eNOS uncoupling, oxidative stress, inflammation and vascular endothelial dysfunction.

Recently, we reported that epidermal growth factor receptor tyrosine kinase (EGFRtk) plays an important role in vascular endothelial dysfunction in type 2 diabetes. Thus, we demonstrated that increased EGFRtk phosphorylation contributes to resistance artery dysfunction in type 2 diabetes [41]. Additionally, previous studies showed that the inhibition of EGFRtk activity promotes vasodilatation and reduces elevated arterial blood pressure in spontaneous hypertensive rat (SHR) and in insulin resistance and hypertensive animal models [42-44]. We recently have demonstrated an increase in EGFRtk activity in type 1 diabetes that is responsible for vascular endothelial dysfunction (unpublished data). Importantly, the inhibition of EGFRtk not only improved vascular endothelial function in type 1 diabetic mice, but also reduced endoplasmic reticulum stress suggesting a relationship between endoplasmic reticulum stress and EGFRtk. Interestingly, the inhibition of endoplasmic reticulum stress also improves vascular endothelial function in type 1 diabetic mice (unpublished data). These results suggest that endoplasmic reticulum stress is down stream signaling to EGFRtk and is an important factor responsible for vascular endothelial dysfunction in type 1 diabetes.

All together, these studies provide evidence that endoplasmic reticulum stress is an important factor in vascular endothelial dysfunction and its inhibition should be considered as a therapeutic strategy to overcome diabetes-induced vascular pathology.

\section{Sources of Funding}

We acknowledge grant support from National Institutes of Health (“1R01HL095566- PI: Dr. Matrougui).

\section{References}

1. Hossain P, Kawar B, EI Nahas M (2007) Obesity and diabetes in the developing world--a growing challenge. N Engl J Med 356: 213-215.

2. Yach D, Stuckler D, Brownell KD (2006) Epidemiologic and economic consequences of the global epidemics of obesity and diabetes. Nat Med 12: 62-66.

3. Palen DI, Matrougui K (2008) Role of elevated EGFR phosphorylation in the induction of structural remodelling and altered mechanical properties of resistance artery from type 2 diabetic mice. Diabetes Metab Res Rev 24: 651 656.

4. Souza-Smith FM, Katz PS, Trask AJ, Stewart JA, Lord KC, et al. (2011). Mesenteric resistance arteries in type 2 diabetic $\mathrm{db} / \mathrm{db}$ mice undergo outward remodeling. PLoS One 6: e23337.

5. Stehouwer CD, Lambert J, Donker AJ, van Hinsbergh VW (1997) Endothelia dysfunction and pathogenesis of diabetic angiopathy. Cardiovasc Res 34: 5568.

6. Hadi HA, Carr CS, Al Suwaidi J (2005) Endothelial dysfunction: cardiovascular risk factors, therapy, and outcome. Vasc Health Risk Manag 1: 183-198.
7. Versari D, Daghini E, Virdis A, Ghiadoni L, Taddei S (2009) Endothelia dysfunction as a target for prevention of cardiovascular disease. Diabetes Care 32: S314-321.

8. Picchi A, Capobianco S, Qiu T, Focardi M, Zou X, et al. (2010) Coronary microvascular dysfunction in diabetes mellitus: A review. World J Cardiol 2 377-390.

9. Shivu GN, Phan TT, Abozguia K, Ahmed I, Wagenmakers A, et al. (2010) Relationship between coronary microvascular dysfunction and cardiac energetics impairment in type 1 diabetes mellitus. Circulation 121: 1209-1215.

10. Zeng G, Nystrom FH, Ravichandran LV, Cong LN, Kirby M, et al. (2000) Roles for insulin receptor, PI3-kinase, and Akt in insulin-signaling pathways related to production of nitric oxide in human vascular endothelial cells. Circulation 101: 1539-1545.

11. Steinberg HO, Chaker H, Leaming R, Johnson A, Brechtel G, et al. (1996) Obesity/insulin resistance is associated with endothelial dysfunction Implications for the syndrome of insulin resistance. J Clin Invest 97: 2601-2610.

12. Wheatcroft SB, Williams IL, Shah AM, Kearney MT (2003) Pathophysiologica implications of insulin resistance on vascular endothelial function. Diabet Med 20: $255-268$

13. Kuboki K, Jiang ZY, Takahara N, Ha SW, Igarashi M, et al. (2000) Regulation of endothelial constitutive nitric oxide synthase gene expression in endothelial cells and in vivo: a specific vascular action of insulin. Circulation 101: 676-681.

14. Montagnani M, Ravichandran LV, Chen H, Esposito DL, Quon MJ (2002) Insulin receptor substrate-1 and phosphoinositide-dependent kinase-1 are required for insulin-stimulated production of nitric oxide in endothelial cells. Mo Endocrinol 16: 1931-1942.

15. Kim JA, Montagnani M, Koh KK, Quon MJ (2006) Reciprocal relationships between insulin resistance and endothelial dysfunction: molecular and pathophysiological mechanisms. Circulation 113: 1888-1904

16. Ozcan U, Yilmaz E, Ozcan L, Furuhashi M, Vaillancourt E, et al. (2006) Chemical chaperones reduce ER stress and restore glucose homeostasis in a mouse model of type 2 diabetes. Science 313: 1137-1140.

17. Zhao L, Ackerman SL (2006) Endoplasmic reticulum stress in health and disease. Curr Opin Cell Biol 18: 444-452.

18. Marciniak SJ, Ron D (2006) Endoplasmic reticulum stress signaling in disease. Physiol Rev 86: 1133-1149.

19. Schroder M, Kaufman RJ (2005) The mammalian unfolded protein response Annu Rev Biochem 74: 739-789.

20. Ron D, Walter $P$ (2007) Signal integration in the endoplasmic reticulum unfolded protein response. Nat Rev Mol Cell Biol 8: 519-529.

21. Kaufman RJ (2002) Orchestrating the unfolded protein response in health and disease. J Clin Invest 110: 1389-1398

22. Ozcan U, Cao Q, Yilmaz E, Lee AH, Iwakoshi NN, et al. (2004). Endoplasmic reticulum stress links obesity, insulin action, and type 2 diabetes. Science 306 : 457-461.

23. Dickhout JG, Hossain GS, Pozza LM, Zhou J, Lhoták S, et al. (2005) Peroxynitrite causes endoplasmic reticulum stress and apoptosis in human vascular endothelium: implications in atherogenesis. Arterioscler Thromb Vasc Biol 25: 2623-2629.

24. Terai K, Hiramoto Y, Masaki M, Sugiyama S, Kuroda T, et al. (2005) AMP activated protein kinase protects cardiomyocytes against hypoxic injury through attenuation of endoplasmic reticulum stress. Mol Cell Biol 25: 9554-9575.

25. Araki E, Oyadomari S, Mori M (2003) Impact of endoplasmic reticulum stress pathway on pancreatic beta-cells and diabetes mellitus. Exp Biol Med 228 1213-1217.

26. Marchetti P, Bugliani M, Lupi R, Marselli L, Masini M, et al. (2007) The endoplasmic reticulum in pancreatic beta cells of type 2 diabetes patients Diabetologia 50: 2486-2494.

27. Scheuner D, Kaufman RJ (2008) The unfolded protein response: a pathway that links insulin demand with beta-cell failure and diabetes. Endocr Rev 29: 317-333.

28. Harding HP, Ron D (2002) Endoplasmic reticulum stress and the development of diabetes: a review. Diabetes 51: S455-S461. 
Citation: Kassan M, Galán M, Choi SK, Matrougui K (2011) Endoplasmic Reticulum Stress and Microvascular Endothelial Dysfunction in Diabetes. J Diabetes Metab 2:108e. doi:10.4172/2155-6156.1000108e

Page 3 of 3

29. McAlpine CS, Bowes AJ, Werstuck GH (2010) Diabetes, hyperglycemia and accelerated atherosclerosis: evidence supporting a role for endoplasmic reticulum (ER) stress signaling. Cardiovasc Hematol Disord Drug Targets 10 $151-157$

30. Amin A, Choi SK, Galan M, Kassan M, Partyka M, et al. (2011) Chronic inhibition of endoplasmic reticulum stress and inflammation prevents ischemia-induced vascular pathology in type II diabetic mice. J Pathol doi: 10.1002/path.3960.

31. Austin RC, Lentz SR, Werstuck GH (2004) Role of hyperhomocysteinemia in endothelial dysfunction and atherothrombotic disease. Cell Death Differ 1 : S56-S64.

32. Gharavi NM, Gargalovic PS, Chang I, Araujo JA, Clark MJ, et al. (2007) High-density lipoprotein modulates oxidized phospholipid signaling in human endothelial cells from proinflammatory to anti-inflammatory. Arterioscler Thromb Vasc Biol 27: 1346-1353.

33. Luo D, He Y, Zhang H, Yu L, Chen $\mathrm{H}$, et al. (2008) AIP1 is critical in transducing IRE1-mediated endoplasmic reticulum stress response. J Biol Chem 283 11905-11912.

34. Zhang K, Kaufman RJ (2008) From endoplasmic-reticulum stress to the inflammatory response. Nature 454: 455-462.

35. Li JM, Shah AM (2004) Endothelial cell superoxide generation: regulation and relevance for cardiovascular pathophysiology. Am J Physiol Regul Integr Comp Physiol 287: R1014-1030.

36. Eringa EC, Stehouwer CDA, Walburg K, Clark AD, Nieuw Amerongen GP, et al. (2006) Physiological concentrations of insulin induce endothelin-dependent vasoconstriction of skeletal muscle resistance arteries in the presence of tumo necrosis factor-\{alpha\} dependence on c-jun n-terminal kinase. Arterioscler Thromb Vasc Biol 26: 274-280.
37. Xue X, Piao JH, Nakajima A, Sakon-Komazawa S, Kojima Y, et al. (2005) Tumor necrosis factor alpha [TNF(alpha)] induces the unfolded protein response (UPR) in a reactive oxygen species (ROS)- dependent fashion, and the UPR counteracts ROS accumulationby TNF(alpha). J Biol Chem 280: 33917-33925

38. Eizirik DL, Cardozo AK, Cnop M (2008) The role for endoplasmic reticulum stress in diabetes mellitus. Endocr Rev 29: 42-61.

39. Zhang K, Kaufman RJ (2008) From endoplasmic-reticulum stress to the inflammatory response. Nature 454: 455-462.

40. Dickhout JG, Hossain GS, Pozza LM, Zhou J, Lhotak S, et al. (2005) Peroxynitrite causes endoplasmic reticulum stress and apoptosis in human vascular endothelium: implications in atherogenesis. Arterioscler Thromb Vasc Biol 25: 2623-2629.

41. Belmadani S, Palen DI, Gonzalez-Villalobos RA, Boulares HA, Matrougui K (2008) Elevated epidermal growth factor receptor phosphorylation induces resistance artery dysfunction in diabetic db/db mice. Diabetes 57: 1629-1637.

42. Fernandez-Patron C (2007) Therapeutic potential of the epidermal growth factor receptor transactivation in hypertension: a convergent signaling pathway of vascular tone, oxidative stress, and hypertrophic growth downstream of vasoactive G-protein-coupled receptors? Can J Physiol Pharmacol 85: 97-104.

43. Hao L, Du M, Lopez-Campistrous A, Fernandez-Patron C (2004) Agonist induced activation of matrix metalloproteinase-7 promotes vasoconstriction through the epidermal growth factor-receptor pathway. Circ Res 94: 68-76.

44. Nagareddy PR, MacLeod KM, McNeill JH (2010) GPCR agonist-induced transactivation of the EGFR upregulates MLC II expression and promotes hypertension in insulin-resistant rats. Cardiovasc Res 87: 177-186. 